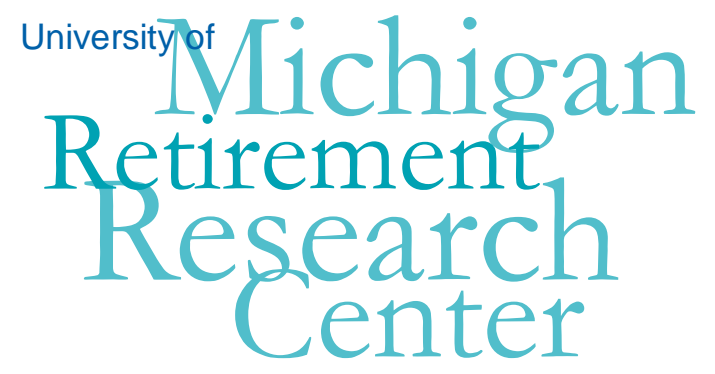

Working Paper

WP 2010-234

\title{
Geographic Dispersion and the Well-Being of the Elderly
}

\author{
Suzanne Bianchi, Kathleen McGarry and Judith Seltzer
}

\begin{tabular}{|l|l|}
\hline $\mathrm{M}$ & $\mathrm{R}$ \\
\hline $\mathrm{R}$ & $\mathrm{C}$ \\
\hline
\end{tabular}

Project \#: UM10-15 


\title{
Geographic Dispersion and the Well-Being of the Elderly
}

\author{
Suzanne Bianchi \\ University of California, Los Angeles \\ Kathleen McGarry \\ University of California, Los Angeles and NBER \\ Judith Seltzer \\ University of California, Los Angeles \\ October 2010 \\ Michigan Retirement Research Center \\ University of Michigan \\ P.O. Box 1248 \\ Ann Arbor, MI 48104 \\ http://www.mrrc.isr.umich.edu/ \\ (734) 615-0422
}

\section{Acknowledgements}

This work was supported by a grant from the Social Security Administration through the Michigan Retirement Research Center (Grant \# 10-M-98362-5-01). The findings and conclusions expressed are solely those of the author and do not represent the views of the Social Security Administration, any agency of the Federal government, or the Michigan Retirement Research Center.

Regents of the University of Michigan

Julia Donovan Darrow, Ann Arbor; Laurence B. Deitch, Bingham Farms; Denise Ilitch, Bingham Farms; Olivia P. Maynard, Goodrich; Andrea Fischer Newman, Ann Arbor; Andrew C. Richner, Grosse Pointe Park; S. Martin Taylor, Gross Pointe Farms; Katherine E. White, Ann Arbor; Mary Sue Coleman, ex officio 


\title{
Geographic Dispersion and the Well-Being of the Elderly
}

\begin{abstract}
Perhaps the largest problem confronting our aging population is the rising cost of health care, particularly the costs borne by Medicare and Medicaid. A chief component of this expense is long-term care. Much of this care for an unmarried (mostly widowed) mother is currently provided by adult children. The provision of family care depends importantly on the geographic dispersion of family members. In this study we provide preliminary evidence on the geographic dispersion of adult children and their older unmarried mother. Coresidence is less likely for married adult children, those who are parents and the highly educated and more likely for those who are not working or only employed part time and for black and Hispanic adult children. Close proximity is more common for married children who are parents but less common for the highly educated. When we look at transitions between one wave of data collection and the next (a 2-year interval), about half of adult children live more than 10 miles away at both points, a little less than one quarter live within 10 miles at both points, and 8 percent are coresident at both points in time. Among the 17 percent who make a transition, about half of the changes result in greater distance between the adult child and mother and half bring them into closer proximity. The needs of both generations are likely reflected in these transitions. In fact, a mother's health is not strongly related to most transitions and if anything, distance tends to be greater for older mothers relative to those mothers in their early 50 s.
\end{abstract}

\section{Authors' Acknowledgements}

The research reported herein was performed pursuant to a grant from the U.S. Social Security Administration (SSA) through the Michigan Retirement Research Center at the University of Michigan (Grant \#10-M-98362-5-02), funded as part of the Retirement Research Consortium with a subcontract to the UCLA. McGarry also gratefully acknowledges support from the National Institute on Aging (R01-AG016593). The opinions and conclusions expressed are solely those of the authors and do not represent the opinions or policy of the Social Security Administration, any agency of the Federal government, the Michigan Retirement Research Center, or UCLA. Authors are listed alphabetically. We thank Arturo Harker and Matthew Hill for countless hours of exceptional research assistance in setting up the data and Jenjira Yahirun for her expert help in analysis. 
The long-term care needs of our aging population will place a substantial burden on our health care system, the finances of the elderly, and the well-being of their families. With nursing homes averaging $\$ 75,000$ a year and 12 hours a day of home care costing about the same, it is not surprising that the majority of care for the frail elderly is provided informally, typically by family members. For the unmarried elderly, care is most often provided by their adult children. Previous research has shown that children who live near a parent (or who co-reside), provide significantly more care than geographically distant children (e.g., Compton and Pollak, 2009; McGarry 1998). However, we know almost nothing about how these living arrangements are chosen. Do children move near a parent with the intention of providing care? Or do geographically proximate children shoulder the burden as a consequence of prior (perhaps unrelated) decisions? Conversely, might parents be the ones to move in order to live closer to children and grandchildren? Previous studies of caregiving that treat the location of parents and children as exogenous, likely suffer from endogeneity bias.

In this study we provide preliminary evidence on the geographic dispersion of parents and their adult children and the factors that are associated with a change in their relative locations. We view this study as the first step in documenting and modeling the geographic dispersion of family members and the role of such living arrangement patterns in the provision of informal home health care. We focus our attention on differences by the child's sex, educational attainment, employment status, marital and parental status and mother's age, health status and race / ethnicity because these have been shown to be strong predictors of eventual caregiving. We find that intergenerational coresidence is less likely for married adult children, those who are parents, and the highly educated, and more likely for those who are not working or only employed part-time and for black and Hispanic adult children. Close proximity is more common 
for married children who are parents but less common for the highly educated. In static comparisons, daughters live closer and more often coreside, once other factors are controlled, but in the transition analysis daughters are not always more likely than sons to move closer to a mother.

When we look at transitions between one wave of data collection and the next (a 2-year interval), about half of adult children live more than 10 miles away at both points, a little less than one quarter live within 10 miles at both points, and 8 percent are coresident at both points in time. Among the 17 percent who make a transition, about half of the changes result in greater distance between the adult child and mother and half bring them into closer proximity. The needs of both generations are likely reflected in these transitions. In fact, a mother's health is not strongly related to most transitions and if anything, distance tends to be greater for older mothers relative to those mothers in their early $50 \mathrm{~s}$.

Our paper is organized as follows. The first section summarizes past work on the topic and highlights the need for data on both children's and parents' characteristics. The second section describes the data we use and the third section presents bivariate descriptive results. A fourth section provides multivariate analysis of the covariates of coresidence and geographic proximity. A fifth section examines correlates of transitions in coresidence and proximity. The final section offers concluding comments and a discussion of directions for future work.

\section{Background}

The vast majority of care received by the elderly is in the form of informal care, with only 8 
percent of needy elderly relying exclusively on formal care ${ }^{1}$ and the estimated value of informal care reaching over $\$ 250$ billion in 2000 , far surpassing the $\$ 100$ billion spent on nursing home care (Arno, Levine, and Memmott, 2002). For the unmarried elderly, children are the most likely caregivers with daughters and daughters-in-law providing substantially more care than sons. ${ }^{2}$ Should these informal networks break down, the additional burden borne by the formal sector would be dramatic.

Previous studies have examined the cost borne by caregivers in terms of time, reduced employment, and mental and physical stress. Lilly, Laporte and Coyte (2007) find that employed caregivers tend to reduce work hours, with larger adjustments if the caregiver lives with the person who needs care. Labor force responses also depend on the intensity of the care that is required. A large number of studies find associations between caregiving and poor health outcomes, such as higher levels of depression, lower self-rated health, more chronic health conditions (Pinquart and Sorensen, 2005; 2007).

As large as these costs are, there are other economic costs that have been overlooked, particularly the potential costs involved in any necessary relocation: either a child relocating to be closer to a parent or the reverse. Given the age at which parents are most likely to need care, such a move by the children would take place during the child's prime working years when they are beginning to prepare for their own retirement. If obligations to a parent force a child to relocate to provide care, the child may retire earlier than anticipated, experiencing a reduction in Social Security and pension benefits, or may change jobs and potentially lose pension benefits and other perquisites of seniority. Conversely, if relocation is not possible and there are no

\footnotetext{
${ }^{1}$ Georgetown Health Policy Institute estimates based on data from the National Health Interview Surveys.

${ }^{2}$ There is an enormous literature on caregiving which we do not summarize here, focusing our discussion instead on co-residence and proximity.
} 
nearby children, a parent may need to employ professional care. The cost of this formal care is substantial and can seriously affect the financial welfare of the elderly individual. If there are insufficient funds available, or the cost of care eventually depletes the individual's savings, formal care will eventually tax Medicare or Medicaid programs. The current study sheds light both on the likelihood of greater parent-child proximity as parents age and examines the characteristics of the child and the parent that make such proximity more likely.

Coresidence and Proximity of Parents and Adult Children: The twentieth century was marked by a rise in independent living. At the start of the century, approximately 60 percent of elderly widows lived with a child, but by the century's end, nearly two-thirds lived alone (McGarry and Schoeni, 2000; Fischer and Hout, 2006). Yet despite this dramatic shift, elderly parents often had a child living nearby. Nearly one quarter of elderly parents lived within one mile of a child, and 60 percent had at least one child located within 10 miles (Lin and Rogerson, 1995).

Geographic proximity depends on the resources and needs of both generations. Declining health and the loss of a spouse appear to increase the proximity of parents and children (Silverstein, 1995; Rogerson, Burr, and Lin, 1997). However, in some cases, the needs of adult children may drive decisions (Michielin, Mulder, and Zorlu, 2008), with adult children who are themselves parents often choosing to locate near their parents for assistance with childcare or for support after a divorce. Other factors also affect residential location such as where children go to college or the labor market opportunities in their particular fields. Children who have a sibling who can help care for a parent may be more mobile than only children who must balance labor market opportunities with potential caregiving responsibilities (Rainer and Siedler, 2009). Firstborns, who make these decisions before their later-born siblings, typically live farther away 
from their parents, presumably leaving the task of future caregiving to younger siblings (Konrad et al., 2002). Although research has shown that blacks and Hispanics are more likely than whites to live with older parents and to view coresidence as desirable (Bianchi et al., 2008), less is known about race / ethnic differences in geographic proximity. Differences in education and family structure may contribute to race / ethnic variation in living arrangements and thus to the costs of caregiving and the welfare of both the parental and child generations. We investigate educational and race / ethnic differences in this paper.

Even in a country as large as the United States, most elderly parents and adult children live near each other. Estimates from the 1987-88 National Survey of Families and Households (NSFH) indicate that 75 percent of older parents live within 25 miles of an adult child, and another 18 percent coreside (Hoyert, 1991). A recent re-analysis of the NSFH data that examined proximity from the adult child's point of view also finds high rates of geographic proximity. Compton and Pollak (2009) show that, for young married couples, the median distance to either of their mothers is within 25 miles. Using data from the Panel Study of Income Dynamics, McGarry and Wiemers (2010) also show that unmarried mothers in their 50s or older are likely to live very near their adult children. The median distance to their closest adult child is just over three miles.

Individuals who are highly educated are more likely to seek employment in a national labor market than those with less education. Labor market opportunities contribute to both cross-sectional and within family differences in how close parents and children live to each other (Rainer and Siedler, 2009; Kalmijn, 2006). Parents and children with less education live closer to each other than those with more education (Kalmijn, 2006; Lin and Rogerson, 1995). Although individuals' residential locations depend on labor market opportunities, community 
and social ties also affect residence choices. Longino et al. (2008) use data on 51 to 61 year olds in the Health and Retirement Study to examine long distance moves. They find that the opportunity to be near children and other family members increases residential mobility. (See Liaw, Frey, and Lin, 2002, for a similar finding using census data.) Ties to kin may also inhibit residential mobility. Spilimbergo and Ubeda's (2004) findings suggest that blacks are less likely than whites to move in response to unemployment because of blacks' greater ties to nearby family members. These ties to a particular geographic area may not only affect labor market outcomes but educational and marriage choices as well and emphasize the importance of understanding socioeconomic and race / ethnic variation in proximity to kin.

Motivations for Geographic Proximity: The research we have cited thus far suggests that the location of kin is one of the factors affecting an individual's decision about where to live. Other studies provide insight into why parents and children might want to live near each other. Parents' need for help and children's ability to provide care are an obvious explanation and several studies have found evidence of this behavior. Rogerson, Burr, and Lin (1997) use longitudinal data from the NSFH to show that increases in parents' functional limitations increase their proximity to adult children. Evidence from the Longitudinal Study of Aging also demonstrates the importance of parents' physical health for geographic proximity to children. Declines in health increase proximity (Silverstein, 1995). Loss of a spouse also increases parents' geographic proximity to adult children (Silverstein, 1995; Rogerson et al., 1997). The adult children too may benefit from coresidence or proximity if the elderly parent provides care for a grandchild or simply helps with chores. In the case of coresidence, both generations also benefit from economies of scale through shared resources and public goods, although some of 
these may be evident for proximate relationships as well (e.g., an older parent may not need a car if a child can help with running errands). Thus, while there are benefits (and costs) accruing to both generations, evidence suggests that as parents age and their health declines, the balance shifts and elderly parents appear to benefit more from coresidence / proximity than do their children (Choi, 2003; Speare and Avery, 1993). Of importance then is a description and understanding of the long-term patterns of living arrangements and geographic proximity and an examination of the changing benefits over time.

One view of coresidence is that it is simply the limiting case of living nearby and that the same motivation applies. However, coresidence might be something altogether different from proximity. Decisions about where to live depend on many factors, including parents' and children's economic resources and health, family values, and attitudes about privacy. Hoyert (1991) and Compton and Pollak (2009) suggest that the two types of living arrangements are in fact, quite distinct by showing that the correlates of coresidence and close proximity differ. An important contribution of our research is that we model how older mothers' health affects both coresidence and geographic proximity to adult children.

Family Characteristics and Proximity: Blacks and Hispanics are more likely to live in multigeneration households than are non-Hispanic whites (Pew, 2010). Among families in which parents and adult children live apart, race-ethnic minorities also appear to help each other more than whites (Hogan et al., 1993).

Large families appear more likely to live near each other and elderly parents are more likely to live near at least one child in larger than smaller families (Crimmins and Ingegneri, 
1990; Rogerson, Burr and Lin, 1997). However, much of this difference likely represents the simple greater opportunity in large families for at least one child to live nearby.

Only a few datasets include information about the geographic proximity of all of a parent's children. Some studies ask about proximity to the nearest child; others ask about the location of a random child. The National Survey of Families and Households, the Panel Study of Income Dynamics, and the Health and Retirement Study all include information about the proximity of more than one child in the parent's family. Rogerson et al. use NSFH data to show that the identity of the closest child often varies over time in families with more than one child. Variation over time in geographic proximity may arise if children "take turns" in caring for a parent. Conversely, children may compete about who is responsible (or not responsible) for providing care (Konrad et al., 2002; Rainer and Siedler, 2009). Older children may exploit their first mover advantage by moving away from parents and leaving younger siblings behind to provide care. Empirical tests of this hypothesis using data from Germany provide conflicting evidence on whether or not firstborns live farther from parents than later born children. There is some evidence, however, that only children live closer to parents than do children with siblings (Rainer and Siedler, 2009), but this pattern may reflect other differences in only-child families (perhaps emotional closeness to parents) rather than simply the need to provide care.

Because women are family "kin keepers" (Hagestad, 1986), having a daughter may increase parents' proximity to children. Evidence consistent with this comes from studies that show that women are more likely than men to care for older family members and to share a home with them (McGarry, 1998; Henretta et al., 1997; Hogan et al., 1993; Wolf and Soldo, 1988). 
Women are also more likely than men to outlive their spouse, making women more reliant on their children for caregiving and support in later life. We, therefore, focus our preliminary analyses on unmarried mothers, nearly all of whom are widowed.

\section{Data and Methods}

Much of the limited research on geographic proximity of families has looked solely at the distance between a parent and a particular child at a single point in time. Little attention has been paid to the evolution of this arrangement. Here we draw on nine waves of data from the Health and Retirement Study (HRS) covering a period of 16 years to examine the distance between older women and their adult children and importantly, to assess the factors that are associated with changes in these living arrangements. ${ }^{3}$

The HRS is an ideal data set for this study in that it focuses on the older population, collects information on the respondents and all of their children (both coresident and noncoresident), and follows these families over an extended period of time. The HRS is administered biennially to a sample that is approximately nationally representative of individuals age 50 or older and their spouses or partners. The survey began in 1992 with a sample of individuals born between the years 1931 and 1941 and their spouses or partners and has since been supplemented with both older and younger cohorts. ${ }^{4}$ The HRS contains extremely detailed information on income, wealth, and health, as well as the usual demographic information including the number of children and step children. In addition to this rich set of demographic and economic measures

\footnotetext{
${ }^{3}$ We do not use the first two waves of the AHEAD survey but do incorporate observations on original AHEAD respondents and their children once that sample is merged with the HRS cohorts in 1998.

${ }^{4}$ An older AHEAD cohort that was first interviewed in 1993 and again in 1995 was merged with the HRS in 1998. These individuals were born in 1921 or earlier. Cohorts of those born between 1924 and 1930 (CODA) and those born between 1942 and 1947 (WB) were also added in 1998 making the sample approximately representative of the
} 
collected for respondents, the survey obtains information on each child's sex, age, educational attainment and school enrollment, marital status, number of own children, whether employed fulltime or part-time, household income, and importantly, whether the child coresides, lives within 10 miles of the parent, or lives farther away. ${ }^{5}$ In the more recent waves of the HRS, the survey collects additional information on which child lives nearest the respondent and if any child lives within a smaller radius of two blocks.

Because our eventual goal is to examine how proximity and caregiving arrangements are determined, we limit this analysis of living arrangements to unmarried elderly women - the demographic group most likely to receive support from a child. For these women we limit our attention to children ages 24 or older. The restriction on children's age reduces the likelihood of our capturing a large number of children who have yet to leave the nest or who are still in college. We also exclude years in which the location of the adult child is missing. These decisions result in an analysis sample of 7,158 mothers and 25,185 adult children. ${ }^{6}$

Most past research on this topic has not distinguished mother-child pairs, but instead has looked at the relationship between a mother and the entire set of her children, asking, for instance, whether the mother has at least one coresident child. Because we are interested in the particular characteristics of a child that are associated with relative location, our analysis is based

population age 50 or older. A refresher sample of individuals in their 50s (born in 1948-1953) was added in 2004 to maintain representativeness. See $\mathrm{http} / / \mathrm{hrsonline}$.isr.umich.edu/ for more details.

${ }^{5}$ The Panel Study of Income Dynamics (PSID) is an alternative data set that can be used to examine changes in family living arrangements over time. Unfortunately, for most of the period covered by the survey, there is little information on the health of the parent and a relatively small sample of elderly respondents. See Hotz et al. (2010) for a similar analysis that does employ the PSID.

${ }^{6}$ In cases in which the HRS respondents split and both individuals are interviewed, there are two (or more) reports on the children. We include children who have two or more "stories" (in HRS terminology), but their inclusion does not affect our results. Because we are focusing on the distances between mothers and children, we select only those "stories" that correspond to the reports of the mother. 
instead on the child level with the observation of interest being mother-child pairs. ${ }^{7}$ Eventually, we will incorporate family fixed effects into the analysis to control for the sex composition and other observable factors on the family level, as well as unobserved differences among families in tastes for coresidence and / or informal caregiving that remain constant over time.

\section{Patterns of Living Arrangements}

Table 1 reports the percentages or means and standard deviations for a number of variables used in the analyses. ${ }^{8}$ As noted above, the data for this table include all child-parent pairs for each wave of the HRS in which the child is 24 years old or older and the child's mother is unmarried and at least 50 years old. The number of observations per child depends on when the child's mother entered the HRS survey and first provided information about the child, her mortality and that of her spouse, and the child's age relative to the mother. Our sample of child-parent pairs provides us with a sample of 94,977 child person years in total, with the number of observations per child ranging from one to nine and with a median number of five interviews. Our sample is fairly old. The mean age for the mothers in this sample is 70 . Consistent with the age of the sample, in about 38 percent of the observations the mother is in fair or poor health.

Table 1 here.

Seventy-one percent of the person years are from children of non-Hispanic white mothers, 17 percent have black mothers and 9 percent have a mother who reports herself to be Hispanic. The mean years of schooling for our sample of children is about 13 years, with only a small fraction of the person years, 3 percent, contributed by those who are still enrolled in school.

\footnotetext{
${ }^{7}$ Preliminary work has examined this issue on the family level. We do not report those results here because they mirror for the most part what has been found in the literature.

${ }^{8}$ The descriptive statistics in Tables 1-7 are weighted estimates. Data in Table 8 and used in the multivariate regression estimates are unweighted.
} 
Nearly 60 percent of our observations are for married children and in 70 percent of the cases the child is a parent herself. Labor force participation of our sample is consistent with other data -70 percent of the time the child is employed full-time and eight percent, part-time.

Table 2 begins to address our question of interest by reporting the distribution of the coresidence and geographic proximity of the parent and child for this stacked sample of child years. We report this distance measure for all children together and separately by the sex of the child. We code our measure of proximity as a categorical variable with possible values: parent and child coreside, parent and child live within 10 miles but are not coresident, and parent and child live more than 10 miles from each other. Because individual children are observed multiple times they may at different times contribute observations to more than one category and even to all three. Perhaps unsurprisingly, the majority of observations correspond to a child living farther than 10 miles from home. In around 60 percent of the observations, the child is living at least 10 miles from a parent. About 30 percent of the time the child lives within 10 miles (but is not coresident), and in the remaining 10 percent, the mother and child coreside. Daughters are slightly more likely to live close to their mothers than sons when not coresiding, but there is no significant difference in the propensity to coreside.

Table 2 here.

It is important to note that because most mothers have more than one child (the mean number of children for our sample of older unmarried women is 3.3) the fraction of mothers with at least one coresident child or with at least one child living within 10 miles is substantially higher than it is for the sample of adult children.

There are notable differences by race and ethnicity in adult children's living arrangements and geographic proximity. As we show in Table 3, only nine percent of the observations are 
from white children who are living in the same household as their mother, compared to 13 percent for non-Hispanic blacks and 15 percent for Hispanics. Whites are also more likely to live outside the 10 mile range than are children from other race / ethnic groups.

Table 3 here.

Caregivers typically have a weaker attachment to the labor force than their noncaregiving siblings and hence we tabulate living arrangements and proximity by the child's employment status. Table 4 shows that sons and daughters who are employed full-time are similar in their likelihood of living with a mother. However, sons who are employed part-time (or not at all) are more likely to coreside than are similarly employed daughters. This finding is consistent with the higher likelihood that daughters have an employed spouse and thus can afford to live independently without full-time employment, whereas, it is less likely for sons to be in such an arrangement. Twenty percent of the observations for sons who are employed part-time are in a coresident situation, compared to approximately 12 percent for daughters. The difference between those not working is of approximately the same magnitude.

Table 4 here.

Married children in the United States rarely live with their parents (Aquilino, 1990), and this pattern is evident in our data as well. Table 5 shows that among our observations on married children only 4 percent of the time are the children living with their mothers. Coresidence is slightly more likely among married daughters than married sons, but it is rare in each case (4.8 vs. 2.9 percent). Among unmarried children, coresidence is much more common with about 20 percent of our observations on unmarried children associated with a coresident arrangement.

Table 5 here.

Obviously, many of these observations are cases in which the living arrangement serves 
primarily to benefit the child. It may be that the child is still in school, has lost a job, or is simply living in the parental household to save money. This pattern is consistent with the associations in Table 6 wherein coresidence is negatively related to the age of the mother. For observations in which the mother is 50-54, just over 15 percent of children are living at home compared to just

over 8 percent by ages 75-79. At the most advanced ages, there is a slight uptick in coresidence, likely indicating a need for assistance on the part of the mother. Age is positively and monotonically related to the likelihood of the children living further than 10 miles away. This relationship is also likely driven more by the situation of the child than the mother, with children likely to move farther away from a mother as they age and find employment.

Table 6 here.

Because we are primarily interested in living arrangements as they relate to the needs of the mother, we address this issue more directly in Table 7 where we examine how geographical proximity is associated with a mother's health. We use self-reported health categories of excellent, very good, good, fair and poor, and calculate the fraction of child-based observations in each living arrangement for each value of the categorical health variable. We see clearly that coresidence is more likely for those observations in which the mother reports being in fair or poor health than when health is excellent to good. However, the differences are small, increasing from 9.4 percent for those in excellent health to 12.4 for those observations in which the mother is in poor health. Although this increase is on the order of a 30 percent gain, it is small in absolute terms.

Table 7 here.

\section{Multivariate Analysis of Living Arrangements and Geographic Proximity}

There are many factors that are associated with the choice of living arrangements, and many of 
these factors are likely to be correlated. We therefore turn to a series of multivariate analyses to examine the relationships between living arrangements and a large number of covariates and to explore predictors of transitions in living arrangements and geographic proximity.

We begin with a simple multinomial logistic regression with our three types of living arrangements as the outcomes. Table 8 shows the coefficients, standard errors, and significance levels for a model predicting the likelihood of coresidence and of living in close proximity (within 10 miles) relative to living farther away (more than 10 miles away). The universe for this model is the stacked number of child person year observations $(\mathrm{N}=94,777)$. We correct the standard errors for the multiple observations on children.

Table 8 here.

Daughters have a higher likelihood than sons of coresiding and of living within 10 miles of a mother, net of other factors and relative to living more than 10 miles from a mother. Married children are less likely to coreside with a mother than unmarried children but there is no significance difference between the married and unmarried in the likelihood of living close to the mother (within 10 miles relative to more than 10 miles away). Being a parent is negatively related to coresidence and positively related to living in close proximity. More highly educated children are less likely to coreside and less likely to live within 10 miles of a mother than less highly educated children. When a child is enrolled in school or works less than full-time or is not employed, the child is more likely to coreside (relative to living far away) than a child who is not enrolled or who is employed fulltime. Not working is associated with a lower likelihood of living nearby (relative to farther away), compared with being employed full-time. As in the bivariate analysis, a mother's advancing age tends to be negatively correlated with coresidence and with closer versus more distant geographic proximity of children. Relative to children of 
white mothers, children of black and Hispanic mothers have a higher likelihood of coresidence. Black children also have a higher likelihood of living within 10 miles rather than further away

from their mother, but the opposite is true for Hispanics who are less likely than white children to live within 10 miles of their mother. This may reflect the relatively high immigrant composition of the Hispanic population. Hispanic mothers who do not live with a child may more often be in the country of origin rather than in the United States, compared with the white population.

\section{Changes in Coresidence and Geographic Proximity}

How stable is coresidence and geographic proximity of adult children and their older mother? In Table 9, we examine transitions between two interview years for the universe of children who are observed in both years. For example, for those children with records for both 1992 and 1994, we examine the cross-tabulation of living arrangements in 1992 by that in 1994 . We do this for eight sets of pairings: 1992-94, 1994-96, 1996-98, 1998-2000, 2000-02, 2002-04, 2004-06, and 2006-08. Summing across these eight transition matrices, Table 9 shows the distribution of the 66,328 consecutive year pairings by whether the living arrangement was stable or whether it changed. In 51 percent of the observations, the child lived more than 10 miles from the mother and remained at this distance. Twenty-three percent of the time, the child lived within 10 miles of the mother and remained close by. In only 8 percent of the cases was a child observed to be living with the mother in two consecutive interviews (a period two years apart). When we examine cells where there was change, in 8 percent of the cases the child was closer to the mother at time 2 (that is, children who lived more than 10 miles away at time 1 and were observed to be either coresident or living within 10 miles at time 2; and children who lived nearby at time 1 and were coresiding at time 2). In 9 percent of the cases, the child was farther from the mother at time 2 (either the child was coresiding at time 1 and was not at time 2 or the 
child lived within 10 miles at time 1 and lived more than 10 miles away at time 2).

Table 9 here.

In order to examine further the factors associated with changes in proximity, we estimated discrete-time event history models in which we take an initial "state" or location and model time to a transition. The discrete-time event history model allows us to use all the data we have on children. We use the stacked data set and allow for time-varying covariates. The analysis is a multinomial logistic regression in which we model the transitions of three groups: those living more than 10 miles from the mother who can transition to a location that is either closer in proximity to a mother or to coresidence; those who live within 10 miles who can transition to a "state" that is farther away (more than 10 miles) or closer (coresidence); and those who are coresiding who can either transition to a state that is geographically proximate or farther away. We are estimating the likelihood of transitioning from one "state" or location to another and how this covaries with a child's and a mother's (time-varying) characteristics. Children are allowed to make multiple transitions and thus to enter into more than one equation. We take into account the multiple observations per child within each initial state-dependent analysis. Children are observed for different amounts of time. The analysis captures changes in time as changes in the mother's age (that is, mother's age is the clock). We do not attempt to identify whether it is the mother or the child (or both) who move, although for ease of exposition our discussion is written as though it is the child who is moving. Appendix Tables A-C provide detailed information on the sample for these regression models.

We begin with person years in which a child is observed to be living more than 10 miles from the mother, the most common living arrangement. We examine whether the mother's health or children's family and work status are associated with the likelihood of moving closer - 
either simply within a 10 mile radius or to coresidence. There are 18,801 children who contribute 57,480 person years of observations, and we observe 4,505 transitions.

We next examine the transitions of children who live within 10 miles of their mother who can transition to coresidence or to a more distant home. The sample for this analysis is based on observations of 10,597 children who contribute 30,198 person years. We observe a total of 4,855 transitions for this group.

The final sample consists of coresident adult children. They are "at risk" of transitioning out of this coresident situation to live either within a 10 mile radius or further away. This analysis is based on observations on 4,062 children who contribute 11,009 person years and for whom we observe 1,665 transitions.

Censoring occurs at the end of the period of observation or when the mother remarries (i.e., is no longer an unmarried mother) or when a mother (or child) dies. Time varying covariates are: mother's health, adult child's marital status, parental status, number of children, school enrollment, and employment status. As noted above, mother's age is the clock for the analysis. Years of schooling completed, race / ethnicity and gender are time invariant. ${ }^{9}$ The analyses take account of clustering at the individual level, but do not take into account that most families are represented by multiple adult children. We will investigate family-level fixed effects in future research.

When Do Children and Mothers Transition To Greater Geographic Proximity? In Table 10 we report the parameters for a discrete time multinomial logistic regression of the outcome -

\footnotetext{
${ }^{9}$ Although we allowed child's years of schooling completed to increase over time, in most cases it was stable and essentially time invariant. This is partly due to our strategy of missing data imputation. We imputed years of
} 
coreside, live within 10 miles, and remain at least 10 miles apart - for those adult children who are observed when they live at least 10 miles from their mother's home. The reference category is remaining in the same location. Once children and mothers live more than 10 miles apart, transitions to coresidence or closer proximity are relatively rare. Only about 8 percent of the observations (i.e., 4505/57,480) make a transition. The results indicate that when mothers' health is poor, children are more likely to transition to coresidence than when mothers are in excellent health. Mother's age is also associated with movements to coresidence. Compared with mothers ages 50-54, those whose mothers are older are more likely to move to coresidence, although the association does not appear to be linear with increasing age of the mother.

Children's characteristics are associated with transitions as well. Married children are less likely to transition to coresidence than unmarried children, but children who are parents themselves are more likely to move to coresidence. Education does not have a statistically significant association with moves from a distant location to coresidence. Children who are employed only part-time or who are not employed at all are more likely to transition to coresidence than those who are employed full-time. Again, this result provides evidence that many of these coresident arrangements are benefiting the child. Finally, there are no statistically significant gender differences in the likelihood of transitioning to coresidence, although in the static comparison in Table 8, daughters were more likely than sons to be coresident or geographically proximate to their mother. That is, beginning states differ by gender but not transition probabilities for those who are geographically distant.

Table 10 here.

Some, but not all, of the same patterns are evident in the associations between mother's

completed schooling from data on that child in previous or future years. For a small subset of cases with missing 
and children's characteristics and transitions to closer proximity. Mother's health is not associated with moves to living within 10 miles of each other, but advancing age does increase the likelihood of transitioning to closer proximity. As for the transition to coresidence, married children are less likely than those who are unmarried to transition to within 10 miles, and parents are more likely to transition to closer proximity than nonparents. Unlike the results for coresidence, the child's education matters, with education reducing the likelihood of a transition to closer proximity. Employment status is not associated with increased proximity. Both blacks and Hispanics are more likely than whites to transition to within 10 miles of their mother.

\section{Is Poor Health of Mothers Associated with Transitions to Coresidence among Children Who} Live Nearby? The parameters in Table 11 come from a multinomial logistic regression in which the outcomes are - coresidence, living more than 10 miles apart, or remaining within 10 miles of each other - for the sample of those who live near, but not with, their mothers. The reference category is remaining within 10 miles. Sixteen percent of the observations $(4,855 / 30,198)$ experience a transition either to coresidence or to beyond 10 miles. Mother's health is not associated with transitions to coresidence when the child already lives close by. Increases in mother's age, however, are associated with increased coresidence, at least compared to mothers in their early 50s. As in the previous table where we examined transitions from a more distant location to coresidence, children who are married are less likely than those who are unmarried to transition to coresidence. Parents are no more likely to move to coresidence than are nonparents. Education also is not associated with transitions to coresidence from nearby, but working less than full-time is associated with an increased likelihood of transitioning to coresidence.

data in all years for a given child, we assigned the sample mean. 
Compared to whites, Hispanics are more likely to move to coresidence, but blacks and whites are similar in their rates of transition to coresidence.

Table 11 here.

Children who are living within 10 miles of their mother are also at risk of living farther away. Surprisingly, when the mother is in fair or poor health children are more likely to transition to farther away than when mothers are in excellent health. It could mean that the mother herself is moving to a situation better suited to her needs, perhaps to a retirement community, an assisted living facility, or nearer to another child. We will investigate this issue in the next phase of our research.

When mothers are older, children are also more likely to live farther away, compared to when mothers are in their early 50s. Married children are less likely to transition to farther apart, and parents are more likely to transition to a greater distance. This finding is puzzling in light of the results in Table 10, which shows that among adult children who are already living more than 10 miles from their mother, being married is associated with a reduced chance of moving nearby. Here we find that marital status reduces the chance of moving farther away. It may be that once married, children become more entrenched in where they are and less likely to relocate to another area. However, these seemingly inconsistent findings point to the importance of looking at children's initial states and taking into account left censoring. Although the HRS does not have a complete residence / proximity history, descriptive analyses should provide insight into what types of children and families contribute to these different analyses.

Those who are not employed are more likely than those who are employed full-time to transition to a more distant location. Women are less likely to move farther away. Compared to whites, blacks and Hispanics are more likely to transition to beyond 10 miles apart. Perhaps 
because we condition on living close by - and whites less often than blacks or Hispanics live close by - those whites who do live near their mother are especially likely to remain in close proximity to her.

Do Adult Children and Mothers Split Up Their Households? The last multivariate analysis uses the sample of child person years in which the child and mother coreside. Fifteen percent of those "at risk" $(1,665 / 11,009)$ move apart, either to households within 10 miles of each other or to a more distant location. Here the dependent variable is: remain in the same household (referent category), live within 10 miles of each other, and live more than 10 miles apart. The results in Table 12 show that when mothers are in poor health, children are significantly less likely to move to a nearby location than when mothers are in excellent health. The negative association between health and household dissolution also occurs for moves to a more distant location, but the coefficient is small and statistically insignificant. When mothers are in their 80 s, children are less likely to transition to a separate household nearby than when mothers are younger. However, when mothers are in their late 50s or sixties, coresiding children are more likely to move either short or long distances from their mother (relative to having a mother in her early 50s). This pattern could be picking up either the mobility of adult children, who do not leave the parental home until relatively late, or the mobility of mothers who may be retiring from the workforce and relocating. We will investigate this further as our research progresses. Married children are more likely than their unmarried counterparts to transition to either within 10 miles or farther away. Education is associated with moves beyond 10 miles, but not with moves within 10 miles. Those who work part-time or are not employed are less likely to move to separate households than those who are working full-time. This pattern is consistent with coresidence as a transfer of 
material resources from the mother to adult child. It is also consistent with children reducing their hours of paid work to provide care for their older mother. We will investigate direct reports about caregiving in these and other arrangements in future research.

Table 12 here.

Daughters are less likely than sons to transition from a shared household to either close or more distant households. Compared to whites, blacks are more likely to transition to nearby locations and Hispanics are less likely to make this transition. Race / ethnicity is not associated with transitions from coresidence to households more than 10 miles apart.

\section{Discussion}

The goal of this research was to shed light on one of the factors that has received little attention in the caregiving literature, the geographic proximity of adult children and parents and how it changes over the later life course. Past work has repeatedly found that coresident children provide the most care for an unmarried elderly parent and when there is no coresident child, a child who lives nearby is often the primary caregiver. However, we know little about how these arrangements come to be - whether they are a result of the need to provide care or determined much earlier in the life course and due to other factors. To begin to tease out this relationship, we look here at a panel of observations on the distance between older women and their children, and examine factors associated with a change in our measures of distance.

In accord with past work, we find large differences in living arrangements by race and ethnicity, with Hispanics being much more likely to coreside, followed by blacks, and with white the least likely. In terms of distance among non-coresident parent-child pairs, white mothers and children also were more likely to live further than 10 miles apart than either blacks or Hispanics. 
We find that coresidence and proximity are related to a mother's health status, although perhaps not as strongly as anticipated. Interestingly, because the transition to adulthood is increasingly delayed, even our restriction to children age 24 or older does not appear to be sufficient to eliminate all of the situations wherein living arrangements and proximity are driven more by the needs of the adult child than the older parent. A high priority for future research is to assess which generation moves and which generation's needs are paramount in the decision to either co-locate or move farther apart.

Our estimates of transitions from one wave to the next show that over 80 percent of adult children do not change distance from their mother over a two-period and that when transitions do occur they are about equally divided between changes that result in greater distance between mother and the adult child (9 percent of the time) and changes that result in the mother and adult child living in closer proximity (8 percent of the time).

Using discrete-time event history methods to assess the likelihood of a transition depending on the child's location (i.e., coresident, within 10 miles, or farther away than 10 miles), we find that when children live more than 10 miles away, they are slightly more likely to transition to coresidence when their mother is in poor than in excellent health, but in general the association with mother's health is weak. Poor health on the part of the mother is not associated with a transition to coresidence when the child is already living in close geographic proximity, that is, within 10 miles of the mother's home. In fact, children who live close by are more likely to transition to greater distance from their mother when her health is only fair or poor compared to when she is in excellent health.

One of the limitations of this analysis is that we have not examined who moves when distance changes. In future research, we plan to give more attention to this issue, the starting 
locations of the adult children, and to the issue of left censoring in the data. We also hope to look at family groups, with attention to siblings and whether where one's siblings are vis-à-vis an older mother is correlated with transitions either closer or farther from the mother. Broadening the range of inquiry to take into all of the children who are potential caregivers - or who might make demands on older mothers' resources - may shed light on how well the needs of older mothers are met. 


\section{REFERENCES}

Aquilino, William S. 1990. "The Likelihood of Parent-Adult Child Coresidence: Effects of Family Structure and Parental Characteristics." Journal of Marriage and the Family, 52: 405-419.

Bianchi, Suzanne M., V. Joseph Hotz, Kathleen McGarry, and Judith A. Seltzer. 2008. "Intergenerational Ties: Theories, Trends, and Challenges." Pp. 3-43 in A. Booth, A. C. Crouter, S. M. Bianchi, and J. A. Seltzer (eds.), Intergenerational Caregiving. Washington DC: Urban Institute Press.

Crimmins, Eileen M. and Dominique G. Ingegneri. 1990. Interaction and Living Arrangements of Older Parents and their Children: Past Trends, Present Determinants, Future Implications. Research on Aging 12 (3): 3-35.

Choi, Namkee G. 2003. "Coresidence between Unmarried Aging Parents and their Adult Children." Research on Aging, 25: 385-404.

Compton, Janice and Robert A. Pollak. 2009. "Proximity and Co-residence of Adult Children: Description and Correlates." Working Paper. http://www.mrrc.isr.umich.edu/publications/papers/pdf/wp215.pdf

Cox, Donald and Oded Stark 2005. "On the Demand for Grandchildren: Tied Transfers, Liquidity Constraints and the 'Demonstration Effect'.” Journal of Public Economics, 89 : 665-697.

Fischer, Claude S. and Michael Hout. 2006. Century of Difference: How America Changed in the Last One Hundred Years. New York: Russell Sage.

Hagestad, Gunhild O. 1986. "The Family: Women and Grandparents as Kinkeepers.” Pp. 14160 in A. Pifer and L. Bronte (eds.), In Our Aging Society. New York: Norton.

Henretta, John C. and Beth Soldo. 2007. "Why Do Families Differ from Each Other? The Case of Adult Children's Parental Care." IZA Workshop on Longterm Care. Bonn, Germany. September, 28-29.

Hogan, Dennis P., David J. Eggebeen, and Clifford C. Clogg. 1993. "The Structure of Intergenerational Exchanges in American Families." American Journal of Sociology, 98: 1428-58.

Hoyert, Donna L. 1991. "Financial and Household Exchanges between Generations." Research on Aging, 13(2): 205-225.

Kalmijn, Matthijs. 2006 "Educational Inequality and Family Relationships: Influences on Contact and Proximity.” European Sociological Review 22(1):1-16. 
Kiecolt-Glaser, Janice K., Ronald Glaser, Stefan Gravenstein, William B. Malarkey and John Sheridan. 1996. "Chronic Stress Alters the Immune Response to Influenza Virus Vaccine in Older Adults." Proceedings of the National Academy of Sciences 93: 3043-3047.

Konrad, Kai A., Harald Künemund, Kjell Erik Lommerud, and Julio R. Robledo. 2002. "Geography of the Family." American Economic Review, 92 (4): 981-998.

Liaw, Kao-Lee, William H. Frey, and Ji-Ping Lin. 2002. "Location of Adult Children as an Attraction for Black and White Elderly Primary Migrants in the United States." Environment and Planning A. 34(2):191-216.

Lilly, Meredith B., Audrey LaPorte and Peter C. Coyte. 2007. "Labor market work and home care's unpaid caregivers: A systematic review of labor force participation rates, predictors of labor market withdrawal, and hours of work." The Milbank Quarterly 85: 641-690.

Lin, Ge and Peter A. Rogerson. 1995. "Elderly Parents and the Geographic Availability of their Adult Children." Research on Aging, 17 (3): 303-331.

Longino, Charles F. Jr., Don. E. Bradley, Eleanor P. Stoller, and William H. Haas, III. 2008. "Predictors of Non-Local Moves Among Older Adults: A Prospective Study." Journal of Gerontology, Social Sciences, 63B(1): S7-S14.

McGarry, Kathleen. 1998. "Caring for the Elderly: The Role of Adult Children.” Pp. 133-63 in D. A. Wise (ed.), Inquiries in the Economics of Aging. Chicago: University of Chicago Press.

McGarry, Kathleen and Emily Wiemers. 2010. "Aging, Care-giving, and Proximity to Mother." Paper presented at the annual meeting of the Population Association of America, Dallas, TX, April.

Michielin, Francesca, Clara H. Mulder, and Aslan Zorlu. 2008. "Distance to Parents and Geographical Mobility.” Population, Space and Place, 14: 327-345.

Pew Research Center for People and the Press. 2010. The Return of the Multi-Generational Family Household. Washington, DC. http://pewsocialtrends.org/assets/pdf/752-multigenerational-families.pdf

Pinquart, Martin and Silvia Sörensen. 2005. "Caregiving Distress and Psychological Health of Caregivers.” In K.V. Oxington (ed), Psychology of Stress, pp. 165-206. New York: Nova Biomedical Books.

Pinquart, Martin and Silvia Sörensen. 2007. "Correlates of Physical Health of Informal Caregivers: A Meta-Analysis." Journal of Gerontology: Psychological Sciences 62B: P126-137. 
Rainer, Helmut and Thomas Siedler. 2009. "O Brother, Where Art Thou? The Effects of Having a Sibling on Geographic Mobility and Labor Market Outcomes.” Economica 76(303): 528-556.

Rogerson, Peter A., Jeffrey A. Burr, and Ge Lin. 1997. "Changes in Geographic Proximity between Parents and their Adult Children.” International Journal of Population Geography, 3: 121-136.

Shapiro, A. 2003. "Later-Life Divorce and Parent-Adult Child Contact and Proximity: A Longitudinal Analysis." Journal of Family Issues, 23, 264-285.

Silverstein, Merril. 1995. "Stability and Change in Temporal Distance between the Elderly and Their Children.” Demography, 32(1):29-45.

Speare, A., Jr. and R. Avery. (1993). "Who Helps Whom in Older Parent-Child Families." Journal of Gerontology, 48: S64-73.

Spilimbergo, A. and L. Ubeda. 2004. "Family Attachment and the Decision to Move by Race." Journal of Urban Economics, $55,478-497$.

Uhlenberg, Peter. 1993. "Demographic Change and Kin Relationships in Later Life." Ed. by George L.Maddox and M. Powell Lawton. Focus on Kinship, Aging, and Social Change. Annual Review of Gerontology and Geriatrics 13: 219-238.

Vedhera, Kav, Nigel K.M. Cox, Gordon K. Wilcock, Paula Perks, Moira Hunt, Stephen Anderson, Stafford L. Lightman and Nola M. Shanks. 1999. "Chronic Stress in Elderly Carers of Dementia Patients and Antibody Response to Influenza Vaccination." The Lancet 353: 627-631.

Wolf, Douglas A. and Beth J. Soldo. 1988. "Household Composition Choices of Older Unmarried Women.” Demography, 25 (3): 387-403. 


\begin{tabular}{|c|c|c|}
\hline & $\begin{array}{r}\text { Mean or } \\
\text { Percentage }\end{array}$ & S.E. \\
\hline \multicolumn{3}{|c|}{ Mother's Traits } \\
\hline Mother's Age & 70.2 & 10.92 \\
\hline \multicolumn{3}{|l|}{ Mother's Health } \\
\hline Excellent & 8.8 & \\
\hline Very good & 23.5 & \\
\hline Good & 30.0 & \\
\hline Fair & 24.3 & \\
\hline Poor & 13.4 & \\
\hline Total & 100.0 & \\
\hline \multicolumn{3}{|l|}{ Mother's Race/Ethnicity } \\
\hline White Non-Hispanic & 71.4 & \\
\hline Black Non-Hispanic & 17.0 & \\
\hline Other Non-Hispanic & 2.5 & \\
\hline Hispanic & 9.2 & \\
\hline Total & 100.0 & \\
\hline \multicolumn{3}{|c|}{ Child's Traits } \\
\hline$\%$ Female & 50.2 & \\
\hline Child's Years of Education & 13.2 & 2.34 \\
\hline \% Enrolled in School & 3.3 & \\
\hline$\%$ Married & 58.0 & \\
\hline \multicolumn{3}{|c|}{ Number of Adult Child's Children } \\
\hline 0 & 30.3 & \\
\hline 1 & 16.5 & \\
\hline 2 & 26.5 & \\
\hline 3 & 15.3 & \\
\hline $4+$ & 11.4 & \\
\hline Total & 100.0 & \\
\hline \multicolumn{3}{|l|}{ Child's Hours Worked } \\
\hline $30+$ HRS & 69.8 & \\
\hline$<30 \mathrm{HRS}$ & 7.8 & \\
\hline Not working & 22.3 & \\
\hline Total & 100.0 & \\
\hline \multicolumn{3}{|l|}{ Year } \\
\hline 1992 & 3.1 & \\
\hline 1994 & 3.2 & \\
\hline 1996 & 3.8 & \\
\hline 1998 & 14.1 & \\
\hline 2000 & 12.1 & \\
\hline 2002 & 14.2 & \\
\hline 2004 & 17.0 & \\
\hline 2006 & 16.2 & \\
\hline 2008 & 16.5 & \\
\hline Total & 100.0 & \\
\hline
\end{tabular}

*Percentage distributions are weighted 
TABLE 2: Proximity to Mother by Child's Gender*

\begin{tabular}{lrrr}
\hline & Male & Female & Total \\
\hline Coresident & 10.2 & 10.4 & 10.3 \\
Within 10 miles & 27.7 & 31.3 & 29.5 \\
More than 10 miles & 62.1 & 58.3 & 60.2 \\
Total & 100.0 & 100.0 & 100.0 \\
Unweighted N & 47,341 & 47,636 & 94,977 \\
\hline
\end{tabular}

*Percentage distributions are weighted 
TABLE 3: Proximity to Mother by Mother's Race/Ethnicity*

\begin{tabular}{lrrrrr}
\hline \hline & White & Black & Other & Hispanic & Total \\
\hline Coresident & 8.7 & 13.4 & 16.2 & 15.2 & 10.3 \\
Within 10 miles & 29.1 & 32.7 & 27.7 & 27.5 & 29.5 \\
More than 10 miles & 62.2 & 53.9 & 56.1 & 57.3 & 60.2 \\
Total & 100.0 & 100.0 & 100.0 & 100.0 & 100.0 \\
N & 58,095 & 23,962 & 2,070 & 10,850 & 94,977 \\
\hline
\end{tabular}

*Percentage distributions are weighted 
TABLE 4: Proximity to Mother by Child's Employment Status and Gender*

\begin{tabular}{|c|c|c|c|c|}
\hline & $30+$ HRS & $<30 \mathrm{HRS}$ & Not working & Total \\
\hline \multicolumn{5}{|l|}{ Full Sample } \\
\hline Coresident & 8.6 & 14.9 & 13.9 & 10.3 \\
\hline Within 10 miles & 30.0 & 29.3 & 28.1 & 29.5 \\
\hline More than 10 miles & 61.4 & 55.9 & 58.0 & 60.2 \\
\hline Total & 100.0 & 100.0 & 100.0 & 100.0 \\
\hline $\mathrm{N}$ & 65,228 & 7,326 & 22,423 & 94,977 \\
\hline \multicolumn{5}{|l|}{ Sons } \\
\hline$\overline{\text { Coresident }}$ & 8.0 & 20.1 & 17.1 & 10.2 \\
\hline Within 10 miles & 28.3 & 25.5 & 25.5 & 27.7 \\
\hline More than 10 miles & 63.6 & 54.4 & 57.4 & 62.1 \\
\hline Total & 100.0 & 100.0 & 100.0 & 100.0 \\
\hline $\mathrm{N}$ & 35,847 & 2,605 & 8,889 & 47,341 \\
\hline \multicolumn{5}{|l|}{ Daughters } \\
\hline Coresident & 9.4 & 12.2 & 12.0 & 10.4 \\
\hline Within 10 miles & 32.0 & 31.2 & 29.7 & 31.3 \\
\hline More than 10 miles & 58.6 & 56.7 & 58.3 & 58.3 \\
\hline Total & 100.0 & 100.0 & 100.0 & 100.0 \\
\hline $\mathrm{N}$ & 29,381 & 4,721 & 13,534 & 47,636 \\
\hline
\end{tabular}

*Percentage distributions are weighted 
TABLE 5: Proximity to Mother by Child's Marital Status and Gender*

\begin{tabular}{|c|c|c|c|}
\hline & Not Married & Married & Total \\
\hline \multicolumn{4}{|l|}{ Full Sample } \\
\hline Coresident & 19.2 & 3.9 & 10.3 \\
\hline Within 10 miles & 26.6 & 31.6 & 29.5 \\
\hline More than 10 miles & 54.3 & 64.5 & 60.2 \\
\hline Total & 100.0 & 100.0 & 100.0 \\
\hline $\mathrm{N}$ & 40,827 & 54,150 & 94,977 \\
\hline \multicolumn{4}{|l|}{ Sons } \\
\hline Coresident & 20.2 & 2.9 & 10.2 \\
\hline Within 10 miles & 23.4 & 30.8 & 27.7 \\
\hline More than 10 miles & 56.4 & 66.2 & 62.1 \\
\hline Total & 100.0 & 100.0 & 100.0 \\
\hline $\mathrm{N}$ & 20,270 & 27,071 & 47,341 \\
\hline \multicolumn{4}{|l|}{ Daughters } \\
\hline Coresident & 18.2 & 4.8 & 10.4 \\
\hline Within 10 miles & 29.7 & 32.4 & 31.3 \\
\hline More than 10 miles & 52.1 & 62.8 & 58.3 \\
\hline Total & 100.0 & 100.0 & 100.0 \\
\hline $\mathrm{N}$ & 20,557 & 27,079 & 47,636 \\
\hline
\end{tabular}

*Percentage distributions are weighted 
TABLE 6: Proximity to Mother by Mother's Age*

\begin{tabular}{|c|c|c|c|c|c|c|c|c|}
\hline & $50-54$ & $55-59$ & $60-64$ & $65-69$ & $70-74$ & $75-79$ & $80+$ & Total \\
\hline Coresident & 15.2 & 13.1 & 11.6 & 10.3 & 8.4 & 8.2 & 8.9 & 10.3 \\
\hline Within 10 miles & 29.5 & 30.4 & 31.6 & 30.1 & 29.8 & 28.9 & 27.3 & 29.5 \\
\hline More than 10 miles & 55.3 & 56.6 & 56.8 & 59.6 & 61.8 & 62.9 & 63.8 & 60.2 \\
\hline Total & 100.0 & 100.0 & 100.0 & 100.0 & 100.0 & 100.0 & 100.0 & 100.0 \\
\hline $\mathrm{N}$ & 4,010 & 12,993 & 15,673 & 14,700 & 13,095 & 11,784 & 22,722 & 94,977 \\
\hline
\end{tabular}

*Percentage distributions are weighted 
TABLE 7: Proximity to Mother by Mother's Health Status*

\begin{tabular}{|c|c|c|c|c|c|c|}
\hline & Excellent & Very good & Good & Fair & Poor & Total \\
\hline Coresident & 9.4 & 9.5 & 9.7 & 11.0 & 12.4 & 10.3 \\
\hline Within 10 miles & 28.8 & 28.5 & 30.1 & 30.1 & 29.3 & 29.5 \\
\hline More than 10 miles & 61.8 & 62.0 & 60.3 & 58.9 & 58.3 & 60.2 \\
\hline Total & 100.0 & 100.0 & 100.0 & 100.0 & 100.0 & 100.0 \\
\hline $\mathrm{N}$ & 7,715 & 21,002 & 28,495 & 24,502 & 13,263 & 94,977 \\
\hline
\end{tabular}


Table 8: Log Odds of an Adult Child Coresiding or Living Within 10 Miles of Mother (Base: Lives more than 10 miles away from mother)

\begin{tabular}{|c|c|c|c|}
\hline & $\mathrm{b}$ & S.E & p-value \\
\hline \multicolumn{4}{|l|}{ Outcome= Coresides } \\
\hline Daughter & 0.160 & 0.043 & 0.000 \\
\hline Child is Married & -1.499 & 0.045 & 0.000 \\
\hline Child is Parent & -0.219 & 0.060 & 0.000 \\
\hline Child's number of children & -0.146 & 0.019 & 0.000 \\
\hline Child's education (in years) & -0.051 & 0.009 & 0.000 \\
\hline Child is enrolled in school & 0.879 & 0.060 & 0.000 \\
\hline \multicolumn{4}{|c|}{ Child's work status (base: $30+$ hours) } \\
\hline$<30$ hours & 0.505 & 0.052 & 0.000 \\
\hline Not working & 0.429 & 0.042 & 0.000 \\
\hline \multicolumn{4}{|l|}{ Mother's Age (base: 50-54) } \\
\hline $55-59$ & -0.142 & 0.056 & 0.010 \\
\hline $60-64$ & -0.198 & 0.062 & 0.001 \\
\hline $65-69$ & -0.272 & 0.065 & 0.000 \\
\hline $70-74$ & -0.407 & 0.070 & 0.000 \\
\hline $75-79$ & -0.474 & 0.072 & 0.000 \\
\hline $80+$ & -0.271 & 0.069 & 0.000 \\
\hline \multicolumn{4}{|c|}{ Mother's Race/Ethnicity (base: white) } \\
\hline Black non-hisp & 0.240 & 0.052 & 0.000 \\
\hline Other non-hisp & 0.387 & 0.142 & 0.006 \\
\hline Hispanic & 0.496 & 0.068 & 0.000 \\
\hline \multicolumn{4}{|c|}{ Mother's Health (base: Excellent) } \\
\hline Very good & 0.040 & 0.063 & 0.530 \\
\hline Good & 0.127 & 0.065 & 0.050 \\
\hline Fair & 0.101 & 0.069 & 0.145 \\
\hline Poor & 0.118 & 0.076 & 0.120 \\
\hline Constant & -0.399 & 0.151 & 0.008 \\
\hline \multicolumn{4}{|c|}{ Outcome=Lives within 10 miles } \\
\hline Daughter & 0.224 & 0.027 & 0.000 \\
\hline Child is Married & 0.024 & 0.026 & 0.354 \\
\hline Child is Parent & 0.247 & 0.035 & 0.000 \\
\hline Child's number of children & -0.002 & 0.009 & 0.867 \\
\hline Child's education (in years) & -0.078 & 0.006 & 0.000 \\
\hline Child is enrolled in school & 0.098 & 0.055 & 0.075 \\
\hline \multicolumn{4}{|c|}{ Child's work status (base: $30+$ hours) } \\
\hline$<30$ hours & -0.019 & 0.037 & 0.596 \\
\hline Not working & -0.121 & 0.027 & 0.000 \\
\hline \multicolumn{4}{|l|}{ Mother's Age (base: 50-54) } \\
\hline $55-59$ & -0.065 & 0.041 & 0.111 \\
\hline $60-64$ & -0.087 & 0.044 & 0.050 \\
\hline $65-69$ & -0.240 & 0.047 & 0.000 \\
\hline $70-74$ & -0.259 & 0.048 & 0.000 \\
\hline $75-79$ & -0.271 & 0.050 & 0.000 \\
\hline $80+$ & -0.308 & 0.049 & 0.000 \\
\hline \multicolumn{4}{|c|}{ Mother's Race/Ethnicity (base: white) } \\
\hline Black non-hisp & 0.193 & 0.032 & 0.000 \\
\hline Other non-hisp & 0.032 & 0.086 & 0.707 \\
\hline Hispanic & -0.179 & 0.043 & 0.000 \\
\hline \multicolumn{4}{|c|}{ Mother's Health (base: Excellent) } \\
\hline Very good & -0.012 & 0.041 & 0.761 \\
\hline Good & 0.023 & 0.042 & 0.587 \\
\hline Fair & 0.022 & 0.044 & 0.622 \\
\hline Poor & -0.008 & 0.047 & 0.871 \\
\hline Constant & 0.205 & 0.096 & 0.033 \\
\hline Log pseudolikelihood & & -81140.4 & \\
\hline $\mathrm{N}$ & & 94,977 & \\
\hline
\end{tabular}


Table 9: Summary of Residential Stability and Change in Adult Children's Proximity to Mother $(\mathrm{N}=66,328)$

\begin{tabular}{lr}
\hline \hline & Percentage \\
\hline Total & 100.0 \\
No Change Time 1 to Time 2 & 82.6 \\
Child lives > 10 miles & 51.3 \\
Child lives within 10 miles & 23.0 \\
Child coresides & 8.0 \\
Child Closer to Mother, Time 2 & 8.1 \\
$>10$ miles to within 10 miles & 6.1 \\
$>$ 10 miles to coresidence & 1.1 \\
Within 10 miles to coresidence & 0.9 \\
Child Farther from Mother, Time 2 & 9.3 \\
Coresidence to within 10 miles & 1.1 \\
Coresidence to $>10$ miles & 1.3 \\
Within 10 miles to > 10 miles & 6.9 \\
\hline
\end{tabular}

Note: Sample restricted to children with valid observations in two

consecutive years. Sum of transitions in 1992-94, 1994-96, 1996-98, 1998-2000, 2000-02, 2002-04, 2004-06, 2006-08 
Table 10: Log Odds of a Child Transitioning to Coresidence or to Within 10 Miles of Mother (Base=More than 10 miles away)

\begin{tabular}{|c|c|c|c|}
\hline & $\mathrm{b}$ & S.E & p-value \\
\hline \multicolumn{4}{|c|}{ Outcome $=$ Transition to coreside } \\
\hline Daughter & -0.109 & 0.076 & 0.151 \\
\hline Child is Married & -1.115 & 0.081 & 0.000 \\
\hline Child is Parent & 0.366 & 0.115 & 0.001 \\
\hline Child's number of children & -0.033 & 0.032 & 0.314 \\
\hline Child's education (in years) & -0.004 & 0.016 & 0.827 \\
\hline Child is enrolled in school & 0.360 & 0.202 & 0.074 \\
\hline \multicolumn{4}{|c|}{ Child's work status (base: $30+$ hours) } \\
\hline$<30$ hours & 0.742 & 0.124 & 0.000 \\
\hline Not working & 0.684 & 0.088 & 0.000 \\
\hline \multicolumn{4}{|l|}{ Mother's Age (base: 50-54) } \\
\hline $55-59$ & 0.739 & 0.268 & 0.006 \\
\hline $60-64$ & 0.594 & 0.269 & 0.027 \\
\hline $65-69$ & 0.874 & 0.266 & 0.001 \\
\hline $70-74$ & 0.402 & 0.277 & 0.147 \\
\hline $75-79$ & 0.573 & 0.275 & 0.037 \\
\hline $80+$ & 0.709 & 0.264 & 0.007 \\
\hline \multicolumn{4}{|c|}{ Mother's Race/Ethnicity (base: white) } \\
\hline Black non-hisp & 0.141 & 0.094 & 0.135 \\
\hline Other non-hisp & 0.141 & 0.257 & 0.584 \\
\hline Hispanic & 0.152 & 0.126 & 0.228 \\
\hline \multicolumn{4}{|c|}{ Mother's Health (base: Excellent) } \\
\hline Very good & 0.112 & 0.171 & 0.512 \\
\hline Good & 0.230 & 0.164 & 0.162 \\
\hline Fair & 0.193 & 0.169 & 0.254 \\
\hline Poor & 0.319 & 0.180 & 0.077 \\
\hline Constant & -5.039 & 0.380 & 0.000 \\
\hline \multicolumn{4}{|c|}{ Outcome=Transition to within 10 miles away } \\
\hline Daughter & 0.099 & 0.035 & 0.004 \\
\hline Child is Married & -0.242 & 0.036 & 0.000 \\
\hline Child is Parent & 0.590 & 0.055 & 0.000 \\
\hline Child's number of children & 0.024 & 0.013 & 0.069 \\
\hline Child's education (in years) & -0.057 & 0.007 & 0.000 \\
\hline Child is enrolled in school & 0.220 & 0.106 & 0.038 \\
\hline \multicolumn{4}{|c|}{ Child's work status (base: 30+ hours) } \\
\hline$<30$ hours & 0.025 & 0.066 & 0.702 \\
\hline Not working & -0.053 & 0.042 & 0.212 \\
\hline \multicolumn{4}{|l|}{ Mother's Age (base: 50-54) } \\
\hline $55-59$ & 0.796 & 0.126 & 0.000 \\
\hline $60-64$ & 0.962 & 0.123 & 0.000 \\
\hline $65-69$ & 0.841 & 0.124 & 0.000 \\
\hline $70-74$ & 0.711 & 0.126 & 0.000 \\
\hline $75-79$ & 0.755 & 0.127 & 0.000 \\
\hline $80+$ & 0.829 & 0.123 & 0.000 \\
\hline \multicolumn{4}{|c|}{ Mother's Race/Ethnicity (base: white) } \\
\hline Black non-hisp & 0.553 & 0.041 & 0.000 \\
\hline Other non-hisp & 0.458 & 0.108 & 0.000 \\
\hline Hispanic & 0.388 & 0.055 & 0.000 \\
\hline \multicolumn{4}{|c|}{ Mother's Health (base: Excellent) } \\
\hline Very good & -0.101 & 0.074 & 0.176 \\
\hline Good & -0.006 & 0.072 & 0.937 \\
\hline Fair & 0.059 & 0.073 & 0.414 \\
\hline Poor & 0.055 & 0.078 & 0.478 \\
\hline Constant & -3.321 & 0.171 & 0.000 \\
\hline Log pseudolikelihood & & -17195.6 & \\
\hline $\mathrm{N}$ & & 57,480 & \\
\hline
\end{tabular}


Table 11: Log Odds of Child Transitioning to Coreside or to More than 10 Miles Away from Mother (Base=Within 10 miles)

\begin{tabular}{|c|c|c|c|}
\hline & $\mathrm{b}$ & S.E. & p-value \\
\hline \multicolumn{4}{|c|}{ Outcome $=$ Transition to coreside } \\
\hline Daughter & 0.035 & 0.086 & 0.685 \\
\hline Child is Married & -1.122 & 0.093 & 0.000 \\
\hline Child is Parent & 0.084 & 0.131 & 0.523 \\
\hline Child's number of children & -0.019 & 0.037 & 0.617 \\
\hline Child's education (in years) & -0.004 & 0.020 & 0.836 \\
\hline Child is enrolled in school & 0.215 & 0.225 & 0.339 \\
\hline \multicolumn{4}{|c|}{ Child's work status (base: $30+$ hours) } \\
\hline$<30$ hours & 0.334 & 0.149 & 0.025 \\
\hline Not working & 0.446 & 0.100 & 0.000 \\
\hline \multicolumn{4}{|l|}{ Mother's Age (base: 50-54) } \\
\hline $55-59$ & 1.148 & 0.317 & 0.000 \\
\hline $60-64$ & 1.460 & 0.312 & 0.000 \\
\hline $65-69$ & 1.427 & 0.318 & 0.000 \\
\hline $70-74$ & 1.131 & 0.326 & 0.001 \\
\hline $75-79$ & 0.899 & 0.335 & 0.007 \\
\hline $80+$ & 1.227 & 0.316 & 0.000 \\
\hline \multicolumn{4}{|c|}{ Mother's Race/Ethnicity (base: white) } \\
\hline Black non-hisp & 0.076 & 0.102 & 0.458 \\
\hline Other non-hisp & -0.374 & 0.359 & 0.298 \\
\hline Hispanic & 0.336 & 0.135 & 0.013 \\
\hline \multicolumn{4}{|c|}{ Mother's Health (base: Excellent) } \\
\hline Very good & -0.124 & 0.173 & 0.473 \\
\hline Good & -0.159 & 0.166 & 0.338 \\
\hline Fair & -0.138 & 0.170 & 0.419 \\
\hline Poor & -0.047 & 0.184 & 0.798 \\
\hline Constant & -4.532 & 0.444 & 0.000 \\
\hline \multicolumn{4}{|c|}{ Outcome=Transition to more than 10 miles away } \\
\hline Daughter & -0.236 & 0.032 & 0.000 \\
\hline Child is Married & -0.305 & 0.034 & 0.000 \\
\hline Child is Parent & 0.243 & 0.050 & 0.000 \\
\hline Child's number of children & 0.026 & 0.012 & 0.033 \\
\hline Child's education (in years) & -0.007 & 0.007 & 0.333 \\
\hline Child is enrolled in school & -0.011 & 0.108 & 0.920 \\
\hline \multicolumn{4}{|c|}{ Child's work status (base: $30+$ hours) } \\
\hline$<30$ hours & 0.064 & 0.064 & 0.314 \\
\hline Not working & 0.109 & 0.040 & 0.006 \\
\hline \multicolumn{4}{|l|}{ Mother's Age (base: 50-54) } \\
\hline $55-59$ & 1.278 & 0.134 & 0.000 \\
\hline $60-64$ & 1.523 & 0.131 & 0.000 \\
\hline $65-69$ & 1.600 & 0.133 & 0.000 \\
\hline $70-74$ & 1.381 & 0.135 & 0.000 \\
\hline $75-79$ & 1.386 & 0.136 & 0.000 \\
\hline $80+$ & 1.397 & 0.132 & 0.000 \\
\hline \multicolumn{4}{|c|}{ Mother's Race/Ethnicity (base: white) } \\
\hline Black non-hisp & 0.339 & 0.038 & 0.000 \\
\hline Other non-hisp & 0.459 & 0.097 & 0.000 \\
\hline Hispanic & 0.636 & 0.046 & 0.000 \\
\hline \multicolumn{4}{|c|}{ Mother's Health (base: Excellent) } \\
\hline Very good & 0.093 & 0.075 & 0.218 \\
\hline Good & 0.124 & 0.072 & 0.088 \\
\hline Fair & 0.196 & 0.073 & 0.007 \\
\hline Poor & 0.267 & 0.077 & 0.001 \\
\hline Constant & -3.402 & 0.172 & 0.000 \\
\hline Log pseudolikelihood & & -14656.0 & \\
\hline $\mathrm{N}$ & & 30,198 & \\
\hline
\end{tabular}


Table 12: Log Odds of Child Transitioning to Within 10 Miles or More than 10 Miles Away from Mother (Base=Coresident)

\begin{tabular}{|c|c|c|c|}
\hline & $\mathrm{b}$ & S.E & p-value \\
\hline \multicolumn{4}{|c|}{ Outcome= Transition to within 10 miles } \\
\hline Daughter & -0.232 & 0.075 & 0.002 \\
\hline Child is Married & 0.790 & 0.091 & 0.000 \\
\hline Child is Parent & 0.196 & 0.111 & 0.077 \\
\hline Child's number of children & 0.085 & 0.035 & 0.016 \\
\hline Child's education (in years) & 0.012 & 0.018 & 0.493 \\
\hline Child is enrolled in school & 0.114 & 0.141 & 0.421 \\
\hline \multicolumn{4}{|c|}{ Child's work status (base: 30+ hours) } \\
\hline$<30$ hours & -0.389 & 0.136 & 0.004 \\
\hline Not working & -0.366 & 0.093 & 0.000 \\
\hline \multicolumn{4}{|l|}{ Mother's Age (base: 50-54) } \\
\hline $55-59$ & 0.969 & 0.192 & 0.000 \\
\hline $60-64$ & 0.881 & 0.192 & 0.000 \\
\hline $65-69$ & 0.669 & 0.201 & 0.001 \\
\hline $70-74$ & 0.179 & 0.222 & 0.419 \\
\hline $75-79$ & -0.329 & 0.252 & 0.191 \\
\hline $80+$ & -0.567 & 0.225 & 0.012 \\
\hline \multicolumn{4}{|c|}{ Mother's Race/Ethnicity (base: white) } \\
\hline Black non-hisp & 0.257 & 0.084 & 0.002 \\
\hline Other non-hisp & -0.363 & 0.280 & 0.195 \\
\hline Hispanic & -0.247 & 0.118 & 0.036 \\
\hline \multicolumn{4}{|c|}{ Mother's Health (base: Excellent) } \\
\hline Very good & -0.118 & 0.149 & 0.429 \\
\hline Good & -0.190 & 0.143 & 0.184 \\
\hline Fair & -0.079 & 0.146 & 0.588 \\
\hline Poor & -0.326 & 0.166 & 0.050 \\
\hline Constant & -3.206 & 0.321 & 0.000 \\
\hline \multicolumn{4}{|c|}{ Outcome $=$ Transition to more than 10 miles away } \\
\hline Daughter & -0.301 & 0.071 & 0.000 \\
\hline Child is Married & 0.525 & 0.087 & 0.000 \\
\hline Child is Parent & 0.165 & 0.103 & 0.109 \\
\hline Child's number of children & 0.050 & 0.033 & 0.131 \\
\hline Child's education (in years) & 0.053 & 0.018 & 0.002 \\
\hline Child is enrolled in school & 0.111 & 0.127 & 0.382 \\
\hline \multicolumn{4}{|c|}{ Child's work status (base: $30+$ hours) } \\
\hline$<30$ hours & -0.214 & 0.124 & 0.084 \\
\hline Not working & -0.084 & 0.083 & 0.309 \\
\hline \multicolumn{4}{|l|}{ Mother's Age (base: 50-54) } \\
\hline $55-59$ & 0.691 & 0.166 & 0.000 \\
\hline $60-64$ & 0.617 & 0.167 & 0.000 \\
\hline $65-69$ & 0.262 & 0.177 & 0.140 \\
\hline $70-74$ & 0.248 & 0.187 & 0.186 \\
\hline $75-79$ & -0.135 & 0.205 & 0.510 \\
\hline $80+$ & -0.260 & 0.186 & 0.162 \\
\hline \multicolumn{4}{|c|}{ Mother's Race/Ethnicity (base: white) } \\
\hline Black non-hisp & -0.007 & 0.082 & 0.930 \\
\hline Other non-hisp & -0.213 & 0.227 & 0.349 \\
\hline Hispanic & -0.087 & 0.102 & 0.395 \\
\hline \multicolumn{4}{|c|}{ Mother's Health (base: Excellent) } \\
\hline Very good & -0.036 & 0.142 & 0.798 \\
\hline Good & -0.080 & 0.137 & 0.561 \\
\hline Fair & 0.001 & 0.139 & 0.996 \\
\hline Poor & -0.041 & 0.153 & 0.789 \\
\hline Constant & -3.379 & 0.290 & 0.000 \\
\hline Log pseudolikelihood & & -5560.3 & \\
\hline $\mathrm{N}$ & & 11,009 & \\
\hline
\end{tabular}


Appendix Table A: Description of Sample for Table 10, Transitions of Children Who Live More than 10 Miles from Mother

\begin{tabular}{lr}
\hline \hline & $\mathrm{n}$ \\
\hline Total person-years in sample & 57,480 \\
Total number of children in sample & 18,801 \\
Number of years each child contributes & \\
1 year & 4,298 \\
2 years & 5,202 \\
3 years & 3,247 \\
4 years & 1,959 \\
5 years & 1,467 \\
6 years & 1,568 \\
7 years & 372 \\
8 years & 338 \\
9 years & 350 \\
Number of children who make a transition & \\
Move to coreside & 725 \\
Move to within 10 miles & 3,780 \\
Total & 4,505 \\
\hline
\end{tabular}

Appendix Table C: Description of Sample for Table 12, Transitions of Children Who Coreside with a Mother

\begin{tabular}{lr}
\hline Total person-years in sample & $\mathrm{n}$ \\
Total number of children in sample & 11,009 \\
Number of years each child contributes & 4,062 \\
1 year & \\
2 years & 946 \\
3 years & 1,507 \\
4 years & 662 \\
5 years & 328 \\
6 years & 270 \\
7 years & 202 \\
8 years & 50 \\
9 years & 34 \\
Number of children who make a transition & 63 \\
Move to within 10 miles & 777 \\
Move to 10+ miles & 888 \\
Total & 1,665 \\
\hline
\end{tabular}

\section{n} 946 28 (20)
Appendix Table B: Description of Sample for Table 11, Transitions of Children Who Live Within 10 Miles of Mother

\begin{tabular}{lr} 
& $\mathrm{n}$ \\
\hline Total person-years in sample & 30,198 \\
Total number of children in sample & 10,597 \\
Number of years each child contributes & \\
1 year & 2,033 \\
2 years & 3,820 \\
3 years & 1,902 \\
4 years & 1,138 \\
5 years & 732 \\
6 years & 576 \\
7 years & 144 \\
8 years & 125 \\
9 years & 127 \\
Number of children who make a transition & \\
Move to Coreside & 585 \\
Move to 10+ miles & 4,270 \\
Total & 4,855 \\
\hline
\end{tabular}

